\title{
Tolerância da soja ao desfolhamento afetada pela redução do espaçamento entre fileiras ${ }^{1}$
}

\author{
Soybean tolerance to defoliation as affected by row spacing reduction
}

\author{
Geovano Parcianello ${ }^{2}$ José Antonio Costa ${ }^{3}$ João Leonardo Fernandes Pires ${ }^{4}$ \\ Lisandro Rambo ${ }^{5}$ Kleiton Saggin 6
}

\section{RESUMO}

A redução do espaçamento entre fileiras de 40 para $20 \mathrm{~cm}$ incrementa a interceptação da radiação, o índice de área foliar e o rendimento de grãos. Este trabalho objetivou avaliar se a redução do espaçamento entre fileiras influencia a tolerância da soja à perda de área fotossintética. O experimento foi conduzido, em semeadura direta na Estação Experimental Agronômica da UFRGS, na safra 2000/01. Utilizou-se o delineamento experimental de blocos ao acaso, com quatro repetições, em parcelas sub-subdivididas. Os tratamentos foram desfolhamento em três estádios de desenvolvimento (V9 - nono nó, R2 - floração e R5 - inicio enchimento de grãos), dois espaçamentos entre fileiras $(20$ e $40 \mathrm{~cm})$ e quatro níveis de desfolhamento (0 - testemunha, 33, 67 e 100\%). Foi utilizada a cultivar FT-Abyara. Os desfolhamentos realizados no período reprodutivo reduziram o rendimento, sendo o estádio $R 5$ o mais crítico. $O$ rendimento médio de grãos da testemunha não desfolhada foi $21 \%$ maior no espaçamento de $20 \mathrm{~cm}\left(4134 \mathrm{~kg} \mathrm{ha}^{-1}\right)$ do que no de $40 \mathrm{~cm}$ (3413 $\left.\mathrm{kg} \mathrm{ha}^{-1}\right)$ e manteve-se sempre superior, em todos os níveis de desfolhamento. O componente que mais influenciou o rendimento foi o número de legumes $\mathrm{m}^{-2}$. Estes resultados indicam que a redução do espaçamento entre fileiras de $40 \mathrm{~cm}$ para $20 \mathrm{~cm}$ é uma prática cultural favorável tanto para as plantas com área foliar intacta quando desfolhadas.

Palavras-chave: Glycine Max (L.) Merrill, rendimento de grãos, estádio de desenvolvimento, arranjo de plantas, área foliar.

\section{ABSTRACT}

The row spacing reduction from 40 to $20 \mathrm{~cm}$ increase radiation interception, leaf area index and grain yield. This experiment aimed to evaluate if the row spacing reduction influence soybean tolerance to loss of photosynthetic area. The research was performed using no-till tillage system at the Agronomic Experimental Station of Universidade Federal do Rio Grande do Sul, during the 2000/01 growing season. Treatments were arranged in a split-split plot randomized complete block design, with four replications. Treatments included five combination of defoliation in three stages of development (V9ninth-node, R2 - full bloom and R5 - beginning of seed filling), two row spacings $(20$ and $40 \mathrm{~cm})$ and four defoliation levels $(0-$ control, 33, 67 and 100\%). The cultivar tested was FT-Abyara. Defoliations performed at the reproductive stages decrease grain yield, especially when curried at the begging of grain filling (R5). The control grain yield was $21 \%$ higher when soybean was sown with rows $20 \mathrm{~cm}$ apart $\left(4134 \mathrm{~kg} \mathrm{ha}^{-1}\right)$ than with $40 \mathrm{~cm}$ rows $(3413 \mathrm{~kg}$ $\left.h^{-1}\right)$. Narrow rows always provided higher yields in all defoliation levels. The component that influenced yield the most was the number of pods $\mathrm{m}^{-2}$. These results indicate that row spacing reduction from $40 \mathrm{~cm}$ to $20 \mathrm{~cm}$ is a positive management strategy for soybean production regardless of defoliation level.

Key words: Glycine max (L.) Merrill, grain yield, growth stages, plant arrangement, leaf area.

\section{INTRODUÇÃO}

A soja é uma planta que suporta determinado nível de redução de área foliar sem que haja decréscimo significativo do rendimento de grãos. A tolerância da soja ao desfolhamento depende do índice de área foliar (IAF), da taxa de fotossíntese, da quantidade de luz interceptada, da distribuição da luz nos estratos da planta e, possivelmente, da partição

\footnotetext{
${ }^{1}$ Parte da dissertação de Mestrado apresentada pelo primeiro autor, para a obtenção do grau de Mestre em Fitotecnia, Faculdade de Agronomia, Universidade Federal do Rio Grande do Sul (UFRGS).

${ }^{2}$ Engenheiro Agrônomo, MSc. E-mail: gparcianello@ig.com.br.

${ }^{3}$ Engenheiro Agrônomo, PhD, Professor do Departamento de Plantas de Lavoura da Faculdade de Agronomia, UFRGS. CP 776, 91501970, Porto Alegre, RS. Pesquisador do CNPq. E-mail: jamc@ufrgs.br.

${ }^{4}$ Engenheiro Agrônomo, Dr., Pesquisador EMBRAPA-Trigo.

${ }^{5}$ Engenheiro Agrônomo, MSc, aluno de doutorado da Faculdade de Agronomia, UFRGS. Bolsista do CNPq.

${ }^{6}$ Aluno do curso de Agronomia da UFRGS. Bolsista do CNPq.
} 
de fotossintatos entre as estruturas vegetativas e reprodutivas (HAILE et al., 1998b).

Insetos-praga desfolhadores atuam modificando a arquitetura do dossel, reduzindo a área foliar efetiva, diminuindo a intercepção da luz, a taxa de crescimento da cultura (TCC), o acúmulo de massa seca (MS) e, conseqüentemente, levando ao decréscimo do rendimento de grãos (HAILE et al., 1998b; GAZZONI \& MOSCARDI, 1998).

A habilidade da soja de evitar redução substancial do rendimento após o desfolhamento depende de vários fatores entre os quais estão a intensidade do desfolhamento; o desenvolvimento fenológico da soja na ocasião do desfolhamento; a habilidade da cultivar em tolerar ou compensar o desfolhamento; os fatores ambientais, como radiação, precipitação e fertilidade do solo (PEDIGO et al., 1986).

Diversas pesquisas foram realizadas variando épocas (desde estádios vegetativos iniciais até reprodutivo final) e níveis (de 0 a 100\%) de desfolhamento, demonstrando desde a não ocorrência de resposta até $87 \%$ de redução no rendimento (BOARD \& HARVILLE, 1998; GRYMES et al., 1999; RIBEIRO \& COSTA, 2000).

Algumas práticas de manejo podem ser utilizadas com a finalidade de aumentar a tolerância da soja ao desfolhamento. Resultados de pesquisas tem mostrado que a redução do espaçamento entre fileiras pode incrementar a massa seca, o IAF, reduzir a competição intraespecífica e, principalmente, possibilitar maior e mais rápida intercepção da radiação solar, em virtude da melhor distribuição das plantas na área, resultando em maior rendimento de grãos (PIRES et al., 1998, THOMAS et al., 1998; VENTIMIGLIA et al., 1999).

Trabalhos realizados com redução no espaçamento entre fileiras de 100 a $17 \mathrm{~cm}$, mostraram acréscimo de até $40 \%$ no rendimento de grãos da soja (HERBERT \& LITCHFIELD, 1982; BULLOCK et al., 1998; PIRES et al., 1998a,b; THOMAS et al., 1998; VENTIMIGLIA et al., 1999). Entretanto, outros autores relataram não ter encontrado aumento no rendimento de grãos com redução do espaçamento entre fileiras (MAEHLER, 2000).

BOARD et al. (1992) e BOARD \& HARVILLE (1996) relatam que o incremento no rendimento de grãos da soja em espaçamento entre fileiras estreito pode ser atribuído ao incremento da intercepção de luz durante o período vegetativo e período reprodutivo inicial (R1 até logo após R5). Uma das consequiências da maior intercepção da radiação é que as folhas da porção inferior da planta, que normalmente não atingem seu potencial fotossintético (JOHNSTON et al., 1969), aumentam a assimilação de $\mathrm{CO}_{2}$.

Assim, a soja poderia tolerar níveis maiores de desfolhamento quando cultivada em espaçamento reduzido entre fileiras do que em espaçamentos amplos, pois as vantagens do espaçamento estreito (tais como maior área foliar e maior acúmulo de MS) permitiriam maior perda de área foliar, resultando na mesma redução da interceptação de luz de plantas menos desfolhadas em espaçamentos mais largos, mantendo o rendimento de grãos equivalente em ambos espaçamentos.

O presente trabalho teve como objetivo avaliar se a redução do espaçamento entre fileiras influencia a tolerância da soja a diminuição de área fotossintética, no sistema de semeadura direta.

\section{MATERIAL E MÉTODOS}

O experimento foi conduzido na Estação Experimental Agronômica da Universidade Federal do Rio Grande do Sul (EEA/UFRGS), localizada no município de Eldorado do Sul, RS. O solo da área experimental pertence à unidade de mapeamento São Jerônimo, classificado com Argissolo Vermelho Distrófico típico (EMBRAPA, 1999).

O delineamento experimental utilizado foi fatorial com parcelas sub-subdivididas, sendo as parcelas principais organizadas em blocos ao acaso, com quatro repetições. Os tratamentos de desfolhamento foram aplicados em três estádios fenológicos de desenvolvimento (V9 - nono nó com folha desenvolvida, R2 - florescimento pleno, R5 início do enchimento de grãos), alocados nas parcelas principais; dois espaçamentos entre fileiras $(20 \mathrm{e}$ $40 \mathrm{~cm}$ ), testados nas subparcelas; e três níveis de desfolhamentos (33, 67 e 100\%) e uma testemunha não desfolhada, arranjadas nas sub-subparcelas.

Os níveis de desfolhamento de 33, 67, $100 \%$ foram obtidos pela remoção manual de um, dois e três folíolos, respectivamente, conservando-se os pecíolos de cada folha trifoliada. Utilizou-se a cultivar "FT-Abyara", de ciclo semi-tardio e hábito de crescimento determinado. $\mathrm{O}$ experimento foi instalado sob sistema semeadura direta, em solo contendo cobertura de 5,8t ha-1 de massa seca de aveia preta, ervilhaca e milho na semeadura.

A adubação de manutenção foi realizada a lanço, com implemento distribuidor acoplado ao trator, precedendo a semeadura, sendo efetuada de acordo com as recomendações da Rede Oficial de Laboratórios de Análise de Solos - ROLAS (BARTZ et al., 1994) e consistiu da aplicação de $250 \mathrm{~kg} \mathrm{ha}^{-1} \mathrm{de}$ 
NPK na fórmula 5-20-20. Algumas características do solo onde foi realizado o experimento foram: teor de argila $=29,0 \% ; \mathrm{pH}$ (em água) $=5,1 ;$ Índice $\mathrm{SMP}=$ 5,$8 ;$ Fósforo $=11,0 \mathrm{mg} \mathrm{L}^{-1}$; potássio $=186,0 \mathrm{mg} \mathrm{L}^{-1}$; matéria orgânica $=2,2 \%(\mathrm{mv})$.

As sementes utilizadas foram tratadas com fungicida Thiabenazole $(15 \mathrm{~g}$ de i.a./100kg de sementes) + Captan (90g de i.a./100kg de sementes) e inoculadas com estirpes específicas de Bradyrhizobium japonicum, em meio turfoso. A semeadura foi realizada na segunda quinzena de novembro, dentro da época preferencial de cultivo para a região, com o uso de uma semeadora de parcelas, regulada para a obtenção de uma população de 40 plantas por $\mathrm{m}^{2}$. $\mathrm{O}$ experimento foi mantido livre de pragas e plantas daninhas.

A caracterização dos estádios de desenvolvimento da soja foi realizada de acordo com a escala proposta por COSTA \& MARCHEZAN (1982). Os estádios de desenvolvimento foram determinados usando as parcelas testemunhas como referência. Considerou-se que as plantas atingiram determinado estádio de desenvolvimento quando $50 \%$ delas, mais uma, apresentavam as características morfológicas descritas na escala num metro linear.

As sub-subparcela tinham dimensões de $6,0 \mathrm{~m} \times 1,6 \mathrm{~m}$, apresentando oito fileiras para o espaçamento de $20 \mathrm{~cm}$ e quatro fileiras para o espaçamento de $40 \mathrm{~cm}$, considerou-se como área útil as quatro fileiras centrais para o espaçamento de $20 \mathrm{~cm}$ e duas fileiras centrais para o espaçamento de $40 \mathrm{~cm}$ de cada sub-subparcela, desprezando $0,5 \mathrm{~m}$ de cada extremidade das fileiras, como bordadura, constituindo uma área útil de $4 \mathrm{~m}^{2}$.

$\mathrm{O}$ rendimento de grãos $\left(\mathrm{kg} \mathrm{ha}^{-1}\right)$ foi obtido por meio da colheita da área útil de cada subsubparcela e corrigido para umidade padrão de $13 \%$. A determinação do número de legumes foi realizada contando-se os legumes produzidos por dez plantas da área útil e transformando-se os valores para unidade de área $\left(\mathrm{m}^{2}\right)$. Considerou-se como legume àquele que apresentava pelo menos um grão formado. O número de grãos por legume foi calculado dividindo-se o número de grãos obtido pelo número de legumes. $\mathrm{O}$ peso do grão (representado pelo peso de 100 grãos) foi obtido pela pesagem de quatro amostras de 100 grãos, coletados aleatoriamente dos grãos colhidos na área útil de cada sub-subparcela, e corrigidos a $13 \%$ de umidade.

Os resultados obtidos foram submetidos à análise de variância utilizando-se o teste F. As diferenças entre médias de tratamentos foram comparadas pelo teste de Duncan ao nível de 5\% de probabilidade para os fatores estádios de desenvolvimento e espaçamento entre fileiras. Os dados dos níveis de desfolhamento foram comparados através da análise de regressão.

\section{RESULTADOS E DISCUSSÃO}

O rendimento de grãos obtido nas parcelas não desfolhadas na média dos dois espaçamento entre fileiras $\left(3774 \mathrm{~kg} \mathrm{ha}^{-1}\right)$, mostra que as condições edafoclimáticas foram favoráveis à obtenção de rendimentos elevados, apesar da deficiência hídrica ocorrida do último decêndio de fevereiro até o segundo decêndio de março, coincidindo com o período do enchimento de grãos da cultura (de R5 até o inicio de R6). Todos os rendimentos obtidos foram superiores ao rendimento médio do Rio Grande do Sul na safra 2000/ $01\left(2300 \mathrm{~kg} \mathrm{ha}^{-1}\right)$, exceto nas parcelas com desfolhamento de 100\% no estádio R5 (Figura 1a e $1 b)$.

O rendimento de grãos dependeu dos níveis de desfolhamento, e a resposta foi diferente dependendo do espaçamento entre fileiras e do estádio em que foi aplicado o desfolhamento. Em ambos os espaçamentos, a resposta do rendimento de grãos à desfolha foi quadrática (Figura 1a). $\mathrm{O}$ rendimento de grãos da testemunha (sem desfolhamento) foi $21 \%$ superior no espaçamento entre fileiras de $20 \mathrm{~cm}$ $\left(4134 \mathrm{~kg} \mathrm{ha}^{-1}\right)$ do que no espaçamento de $40 \mathrm{~cm}$ (3413 $\left.\mathrm{kg} \mathrm{ha}^{-1}\right)$. A superioridade do espaçamento reduzido para rendimento de grãos se manteve em todos os níveis de desfolhamento.

Analisando-se a figura 1a e baseando-se nas equações obtidas para os espaçamentos, pode-se determinar o nível máximo de desfolhamento que a planta tolera no espaçamento de $20 \mathrm{~cm}$, mantendo rendimentos superiores aos da testemunha de $40 \mathrm{~cm}$. Neste sentido, verificou-se que a soja no espaçamento de $20 \mathrm{~cm}$ suportou desfolha de até $88 \%$ ainda apresentando rendimentos iguais, ou superiores aos obtidos no espaçamento de $40 \mathrm{~cm}$, na média dos três estádios de desenvolvimento desfolhados. Ainda na figura 1a, verifica-se também, que o ponto de máximo rendimento calculado para o espaçamento de $20 \mathrm{~cm}$ foi de $4387 \mathrm{~kg} \mathrm{ha}^{-1}$ com um desfolhamento de $28 \%$, sendo superior ao ponto de máxima para o espaçamento de $40 \mathrm{~cm}\left(3486 \mathrm{~kg} \mathrm{ha}^{-1}\right)$ com $24 \%$ de desfolhamento. Observa-se também que os rendimentos de grãos foram significativamente superiores no espaçamento de $20 \mathrm{~cm}$ em relação aos do espaçamento de $40 \mathrm{~cm}$ nos tratamentos com desfolha de $33 \%$, $67 \%$ e $100 \%$ e na testemunha. Os resultados obtidos permitem que se afirme que a 
redução do espaçamento é uma prática favorável ao rendimento de grãos tanto em plantas com área foliar intacta quanto nas desfolhadas.

Os dados mostram que houve melhor desempenho da soja em espaçamento reduzido, mesmo quando desfolhada, confirmando dados obtidos por PIRES et al. (1998), em relação aos efeitos desta prática cultural no mesmo local. Estes autores atribuíram os maiores rendimentos de grãos verificados em fileiras distanciadas de $20 \mathrm{~cm}$ ao melhor arranjo de plantas, o que provavelmente reduziu a competição intraespecífica, principalmente por luz, proporcionando incremento do IAF, fechamento mais rápido do espaço entre fileiras, maior e mais rápida intercepção da radiação incidente, e melhor aproveitamento dos recursos ambientais.

A resposta do rendimento de grãos dependeu dos níveis de desfolhamento e do estádio de desenvolvimento em que o mesmo foi realizado (Figura 1b). O rendimento de grãos apresentou desde acréscimo de $21 \%$ para $33 \%$ de desfolhamento no estádio V9 $\left(4570 \mathrm{~kg} \mathrm{ha}^{-1}\right)$ até redução de $82 \%$ para $100 \%$ de desfolhamento em R5 (699kg ha-1), em relação à testemunha $\left(3774 \mathrm{~kg} \mathrm{ha}^{-1}\right)$.

Não houve efeito significativo do desfolhamento sobre o rendimento de grãos quando este foi realizado em $\mathrm{V} 9$, na média dos dois

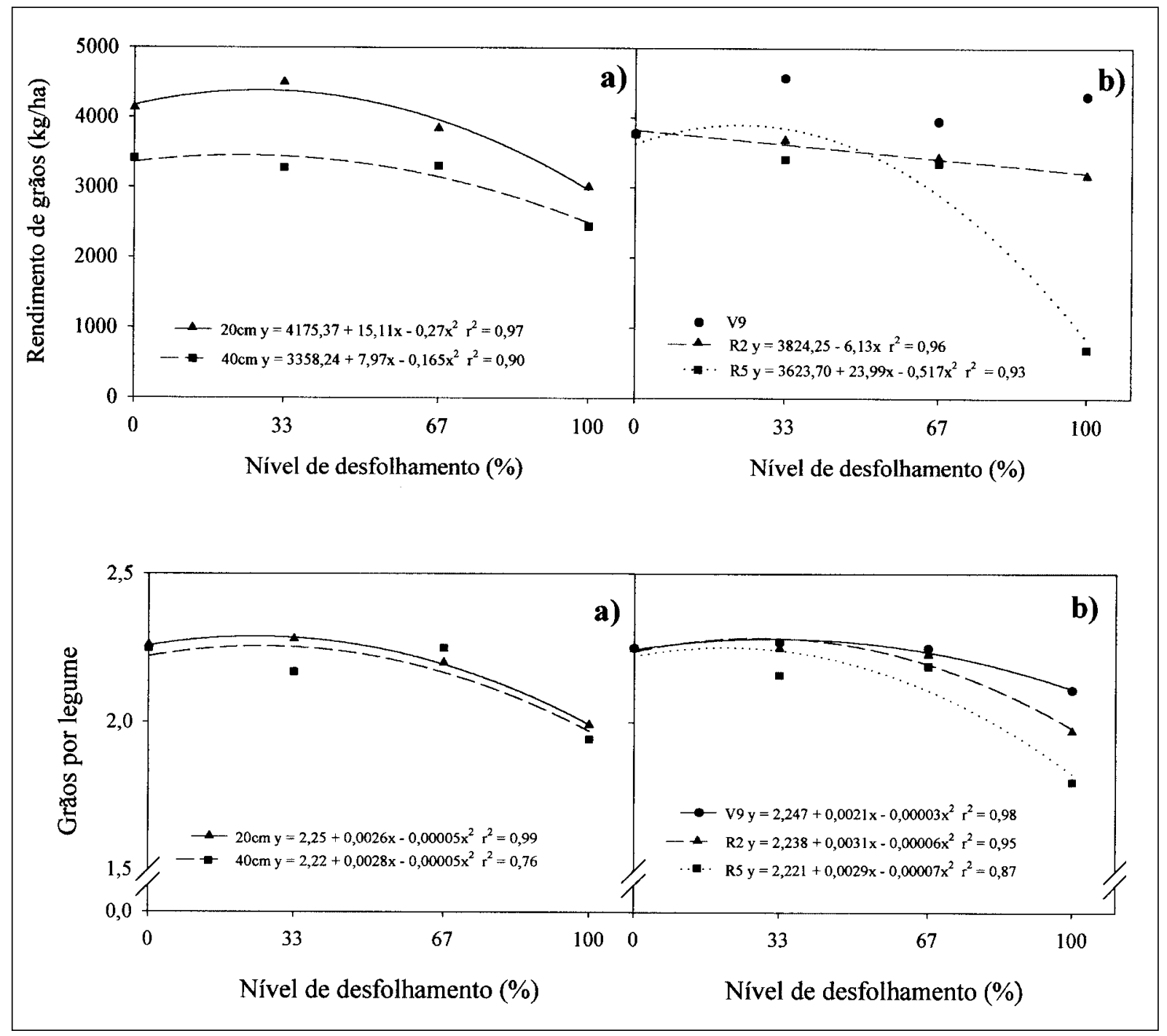

Figura 1 - Rendimento de grãos $\left(\mathrm{kg} \mathrm{ha}^{-1}\right)$ e número de grãos por legume, da cultivar de soja FT-Abyara, em quatro níveis de desfolhamento e dois espaçamentos entre fileiras, na média dos três estádios de desenvolvimento (a); e em três estádios de desenvolvimento, na média de dois espaçamentos entre fileiras (b), EEA/UFRGS, Eldorado do Sul, RS, 2000/01.

Ciência Rural, v.34, n.2, mar-abr, 2004. 
espaçamentos entre fileiras (Figura 1b). No estádio $\mathrm{R} 2$, verificou-se comportamento linear decrescente do rendimento, à medida que aumentaram os níveis de desfolhamento. Desta forma, qualquer perda de área foliar neste estádio acarretou perdas de rendimento de grãos, mesmo com a recuperação de parte da área foliar. A resposta quadrática do rendimento aos níveis de desfolhamento dentro do estádio R5 (Figura 1b) revela que para níveis baixos de desfolhamento o rendimento se mantém estabilizado. À medida que os níveis de desfolhamento aumentam, tem-se maior redução do rendimento, havendo decréscimos acentuados com desfolhas superior a $67 \%$.

As perdas de até $82 \%$ no rendimento com $100 \%$ de desfolhamento, no estádio R5, indicaram que a soja não consegue mais recuperar a área fotossintética, no enchimento de grãos. Isto resulta em menor fonte de fotoassimilados, limitando o desenvolvimento das estruturas reprodutivas (demanda). Conforme relatado por INGRAM et al. (1981), o efeito do desfolhamento sobre o rendimento de grãos demonstrou ter sido causado pela redução da interceptação da luz (IL) e fotossíntese do dossel. Outro fator que pode ter contribuído para a queda do rendimento foi a insuficiência de reservas que as plantas possuíam nos caules, ramos e pecíolos, para suprir a demanda das estruturas reprodutivas, mesmo permanecendo parte da área foliar como aconteceu no nível de $67 \%$ de desfolhamento.

A perda de rendimento dos tratamentos desfolhados em R2 e R5 pode ter sido agravada pelo déficit hídrico registrado durante o estádio R5, que provavelmente diminuiu a retomada do crescimento das plantas e acelerou a senescência das folhas. Neste sentido, HAILE et al. (1998a), em trabalho conduzido com cultivares de soja de hábito de crescimento indeterminado e níveis de desfolhamento no estádio $\mathrm{R} 2$, reportaram que num ano com precipitação adequada o rendimento de grãos não foi alterado pela desfolha, pois as plantas compensaram a perda de área foliar via atraso na senescência foliar, e retomada do crescimento, com aumento da capacidade de interceptação de luz do dossel desfolhado. Já num ano com menor precipitação, o desfolhamento causou redução significativa do rendimento (15 a 70\%) em todas as cultivares de soja. Os resultados deste trabalho indicam que o desfolhamento no estádio R5 foi o mais critico ao rendimento de grãos da soja, mesmo em ano favorável à obtenção de altos tetos de rendimento.

O comportamento do rendimento de grãos da soja em função dos tratamentos realizados pode ser melhor entendido pela análise dos componentes do rendimento. O número de legumes por $\mathrm{m}^{2}$ (Figura 2a) aumentou linearmente em função do incremento de desfolha, quando esta foi realizada em V9, no espaçamento entre fileiras de $40 \mathrm{~cm}$. O número de legumes por $\mathrm{m}^{2}$ (Figura $2 \mathrm{~b}$ ) aumentou com o nível baixo de desfolhamento e decresceu com os níveis maiores de desfolhamento quando a desfolha foi realizada em R2. Entretanto, o número de legumes no espaçamento de $20 \mathrm{~cm}$ sempre foi superior ao encontrado no espaçamento de $40 \mathrm{~cm}$. A desfolha realizada em $\mathrm{R} 5$ afetou quadraticamente o número de legumes por área para o espaçamento de $20 \mathrm{~cm}$ (Figura 2c). Este manteve-se inicialmente estável e decresceu com níveis maiores de desfolhamento. Já para o

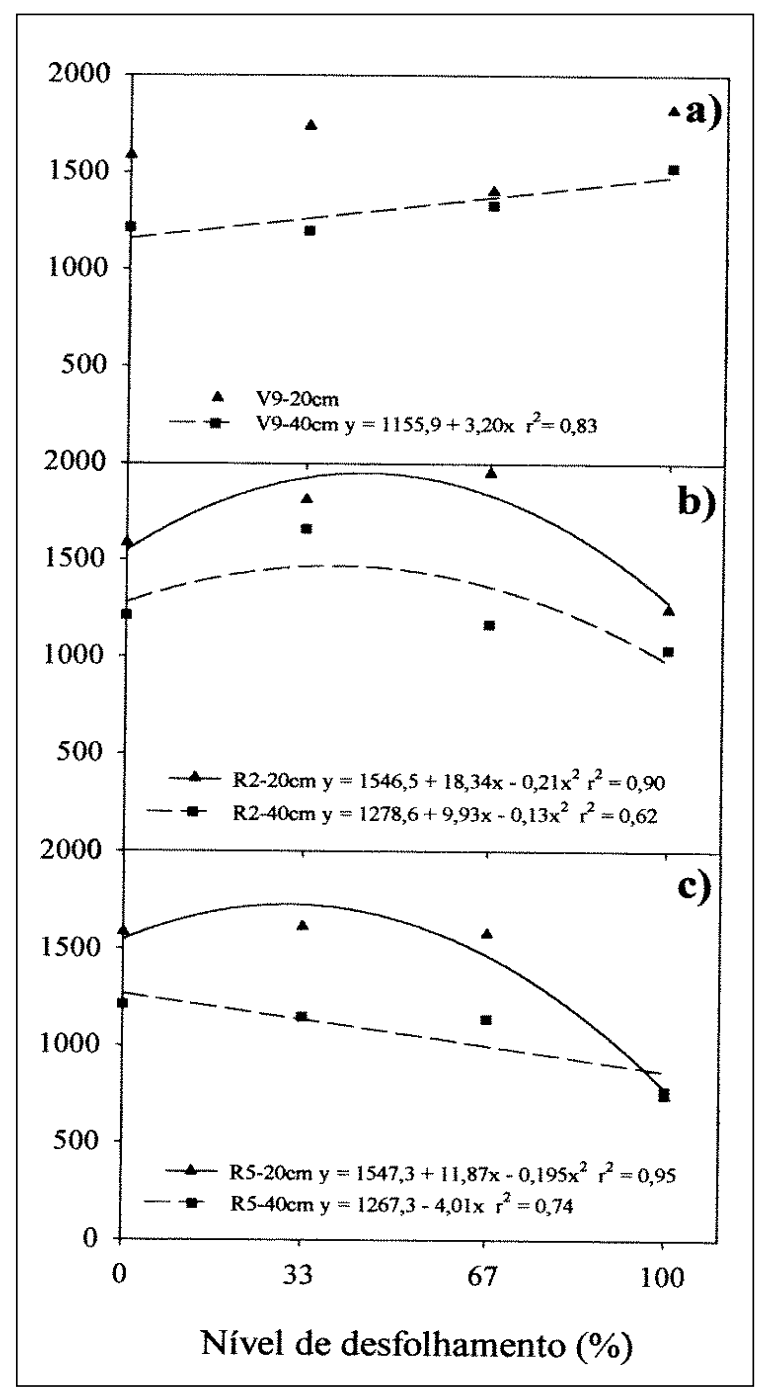

Figura 2 - Número de legumes por $\mathrm{m}^{2}$, da cultivar de soja FTAbyara, em quatro níveis de desfolhamento nos estádios V9 (a), R2 (b) e R5 (c), dois espaçamentos entre fileiras, EEA/UFRGS, Eldorado do Sul, RS, 2000/01.

Ciência Rural, v.34, n.2, mar-abr, 2004. 
espaçamento de $40 \mathrm{~cm}$, observou-se resposta linear com decréscimo do número de legumes à medida que os níveis de desfolhamento aumentaram.

Esses dados demonstram que houve efeito benéfico da pequena remoção de área foliar sobre o número de legumes por $\mathrm{m}^{2}$, em ambos os espaçamentos, e em todos os estádios, com exceção do estádio R5 no espaçamento de $40 \mathrm{~cm}$. Este benefício se refletiu no rendimento de grãos, como mostra a figura 1a. Possivelmente um dos fatores que pode ter contribuído para o aumento do número de legumes foi o aumento da incidência de luz no interior do dossel que possibilitou maior fixação de legumes e, conseqüentemente, maior rendimento de grãos, principalmente para o espaçamento de $20 \mathrm{~cm}$.

Fatores como a densidade de plantas, ciclo da cultivar e nível de fertilidade do solo utilizados no presente trabalho podem estar relacionado com os efeitos positivos de desfolha moderada sobre a penetração de luz, fixação de legumes e rendimento de grãos, pois são fatores que podem afetar o crescimento e a plasticidade da soja.

Trabalho realizado por MATHEW et al. (2000), com enriquecimento de luz em estádios de desenvolvimento da soja, indicou aumento no rendimento devido principalmente ao aumento do número de legumes. Segundo os autores, o enriquecimento de luz, imposto durante os estádios iniciais de desenvolvimento da soja, poderia incrementar a disponibilidade de fotoassimilatos para o desenvolvimento de estruturas reprodutivas, e reduzir o aborto de flores e a abscisão de legumes resultando em maior número final de legumes.

No entanto, para níveis altos de desfolhamento, observou-se resposta distinta do número de legumes por $\mathrm{m}^{2}$. Níveis altos de desfolhamento no período vegetativo para o espaçamento de $40 \mathrm{~cm}$ beneficiaram o número de legumes, pois a soja teve a capacidade de recuperar a área foliar, e desenvolver as estruturas reprodutivas. Já para o período reprodutivo, níveis altos de desfolhamento nos dois espaçamentos resultaram em decréscimo do número de legumes.

Essa resposta demonstra que os desfolhamentos no período reprodutivo foram mais críticos à planta, principalmente os realizados no estádio R5, os quais comprometeram o número de legumes por $\mathrm{m}^{2} \mathrm{e}$, através deste, o rendimento de grãos. Neste caso, as plantas não se recuperaram suficientemente para a reposição das estruturas vegetativas. Comprometendo-se a formação das mesmas, elas não possuíam reservas suficientes para a manutenção e desenvolvimento dos legumes, fato este também observado por PISSAIA \& COSTA, (1981).

Com a redução do espaçamento entre fileiras há um incremento na TCC até aproximadamente o estádio R5, devido ao incremento do IAF que propicia maior número de legumes (BULLOCK et al., 1998). Para BOARD et al. (1992), o incremento do rendimento em espaçamentos estreitos se deve à maior produção de legumes gerada pelo efeito do aumento na intercepção de luz, e TCC, do período vegetativo inicial ao reprodutivo final, promovendo maior número de nós férteis $\mathrm{m}^{2}$, e/ou de legumes por nó fértil.

A resposta do número de grãos por legume ao desfolhamento foi quadrática nos dois espaçamentos entre fileiras e três estádios de desenvolvimento avaliados. Este componente do rendimento manteve-se estável nos níveis baixos de desfolhamento e reduziu-se com o aumento da redução de área foliar (Figura 1a e 1b), principalmente quando este foi feito na fase reprodutiva da cultura.

Este componente foi pouco afetado pela redução do espaçamento entre fileiras, provavelmente porque é determinado durante o período reprodutivo final da planta. Neste período, não há diferenças na massa seca e IAF da soja com a redução do espaçamento entre fileiras (PIRES et al., 1998), indicando que pode ocorrer um provável equilíbrio da relação fonte-demanda nos dois espaçamentos, justificando a semelhança obtida do número de grãos por legume.

O peso médio de 100 grãos não foi afetado pelos espaçamentos entre fileiras no presente trabalho. Este resultado também foi obtido por PIRES et al. (1998) e MAEHLER (2000), em trabalho avaliando os mesmos espaçamentos entre fileiras, no mesmo local.

Houve efeito significativo da interação entre estádio de desenvolvimento e níveis de desfolhamento sobre o peso de 100 grãos. No estádio V9, não houve variação do peso do grão com os níveis de desfolhamento. Para os estádios R2 e R5, a resposta foi quadrática, porém com inclinações opostas (Figura 3). No estádio R2, observou-se, inicialmente, decréscimo do peso do grão para níveis baixos de desfolhamento e aumento com a elevação dos níveis de desfolhamento. Já no estádio R5, o peso do grão se manteve estável para níveis baixos de desfolhamento e decresceu, acentuadamente, para níveis altos de desfolhamento.

A variação do peso do grão para o desfolhamento no estádio R2 pode ser explicada pela recuperação, em parte, da área foliar e pelo

Ciência Rural, v.34, n.2, mar-abr, 2004. 


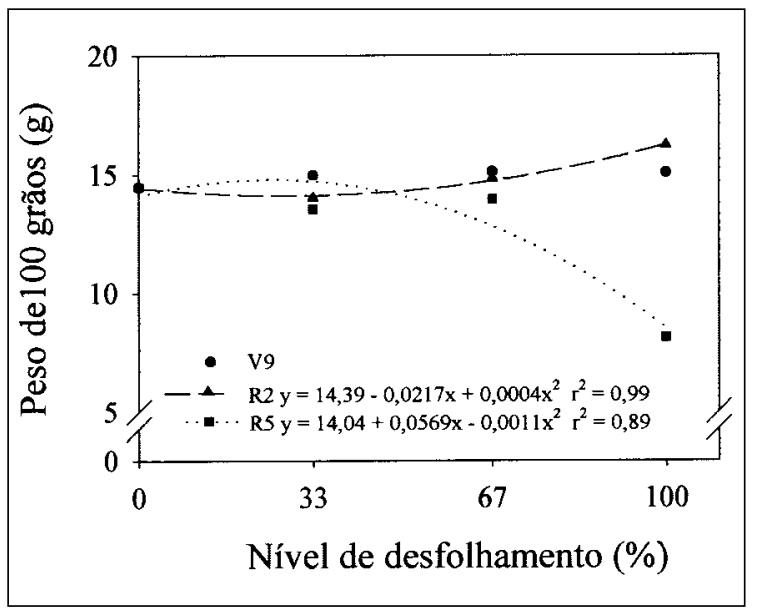

Figura 3 - Peso de 100 grãos, da cultivar de soja FT-Abyara, em quatro níveis de desfolhamento e três estádios de desenvolvimento, na média de dois espaçamentos entre fileiras, EEA/UFRGS, Eldorado do Sul, RS, 2000/01.

retardamento na senescência das folhas das plantas desfolhadas; além de as plantas possuírem menor número de fontes de demanda, comparadas à testemunha, provavelmente promovido pelo maior aborto de flores e abscisão dos legumes. Assim, podese deduzir que o incremento do peso do grão verificado para os níveis altos de desfolhamento decorreu de uma maior relação fonte-demanda. Porém, essa compensação do maior peso do grão pelo menor número de legumes não foi o suficiente para manter o rendimento de grãos, sugerindo que, em certas condições, a redução do rendimento de grãos promovido pelo desfolhamento durante o período efetivo de enchimento dos grãos, pode ser mais restringido pela demanda do que pela fonte, como foi observado principalmente no desfolhamento de $100 \%$. Quanto à redução do peso do grão, resultante do desfolhamento no estádio R5, a planta, quando perdeu parte ou todas as folhas, não teve a capacidade de produzir folhas novas, tendo que suprir a demanda dos grãos com as reservas das estruturas vegetativas que possuía e com menor fonte de assimilados, acarretando baixo peso do grão. Segundo BOARD \& HARVILLE (1998), o mecanismo de remobilização tem um importante papel na formação do rendimento de grãos da soja, e na manutenção do rendimento quando estresses, como o desfolhamento, ocorrem durante o período efetivo de enchimento de grãos.

Assim, o número de legumes por $\mathrm{m}^{2}$ foi o componente do rendimento mais responsivo aos tratamentos impostos, demonstrando a capacidade da planta em se ajustar às diferentes condições de manejo.
Este componente do rendimento, segundo vários autores, é o que sofre maior variação, tanto em trabalhos com espaçamento entre fileiras (BOARD et al., 1992; PIRES et al., 1998; THOMAS et al., 1998), como em trabalhos com níveis e estádios de desenvolvimento desfolhados (BOARD \& TAN, 1995; GAZZONI \& MOSCARDI, 1998).

\section{CONCLUSÕES}

Nas condições em que foi conduzido o experimento, e com a cultivar de soja testada concluise que a redução do espaçamento entre fileiras de 40 para $20 \mathrm{~cm}$, em semeadura direta, propicia maior rendimento de grãos da soja tanto para plantas com área foliar intacta quanto desfolhadas.

O maior rendimento de grãos no espaçamento reduzido ocorre devido ao aumento do número de legumes por $\mathrm{m}^{2}$.

O inicio do enchimento de grãos (R5) é o estádio mais crítico à perda de área fotossintética, resultando em decréscimo do rendimento ocorre à medida que aumenta a intensidade do desfolhamento, nos estádios reprodutivos.

\section{REFERÊNIAS BIBLIOGRÁFICAS}

BARTZ, H.R. (Coord). Recomendações de adubação e calagem para os estados do Rio Grande do Sul e de Santa Catarina. Passo Fundo : SBCS-Núcleo Regional Sul, 1994. 224p.

BOARD, J.E.; KAMAL, M.; HARVILLE, B.G. Temporal importance of greater light interception to increased yield in narrow-row soybean. Agronomy Journal, Madison, v.84, n.4, p.575-579, 1992.

BOARD, J.E.; TAN, Q. Assimilatory capacity effects on soybean yield components and pod number. Crop Science, Madison, v.35, n.3, p.846-851, 1995.

BOARD, J.E.; HARVILLE, B.G. Growth dynamics the vegetative period affects yield of narrow-row, late-planted soybean. Crop Science, Madison, v.88, n.4, p.567-572, 1996.

BOARD, J.E.; HARVILLE, B.G. Late-planted soybean yield response to reproductive source/sink stress. Crop Science, Madison, v. 38, n.3, p. 763-771, 1998.

BULLOCK, D.; KHAN, S.; RAYBURN, A. Soybean yield response to narrow rows is largely due to enhanced early growth. Crop Science, Madison, v.38, n.4, p.1011-1016, 1998.

COSTA, J.A.; MARCHEZAN, E. Características dos estádios de desenvolvimento da soja. Campinas : Fundação Cargil, 1982. 30 .

EMBRAPA. Centro Nacional de Pesquisas de Solos. Sistema Brasileiro de Classificação de Solos. Brasília : EMBRAPA, 1999. 412p.

Ciência Rural, v.34, n.2, mar-abr, 2004. 
GAZZONI, D.L.; MOSCARDI, F. Effect of defoliation levels on recovery of leaf area, on yield and agronomic traits of soybeans. Pesquisa Agropecuária Brasileira, Brasília, v.33, n.4 p.411-424, 1998.

GRYMES, C.F. et al. Soybean response to weed interference and defoliation. Weed Science, Champaign, v.47, n.1, p.90-94, 1999.

HERBERTM, S.J.; LITCHFIELD, G.V. Partitioning soybean seed yield components. Crop Sciense, Madison, v.22, n.5, p.10741079, 1982.

HAILE, F.J.; HIGLEY, L.G.; SPECHT, J.E. Soybean cultivars and insect defoliation: Yield loss and economic injury levels. Agronomy Journal, Madison, v.90, n.3, p.344-352,1998a.

HAILE, F.J. et al. Soybean leaf morphology and defoliation tolerance. Agronomy Journal, Madison, v.90, n.3, p.353-362, $1998 b$.

INGRAM, K.T. et al. Effects of defoliating pests on soybean canopy $\mathrm{CO}_{2}$ exchange and reproductive growth. Crop Science, Madison, v.21, n.2, p. 961-968, 1981.

JOHNSON, T.J. et al. Influence of supplemental light on apparent photosynthesis, yield, an yield components of soybeans (Glycine max L.). Crop Science, Madison, v.9, n.5, p.577-581, 1969.

MAEHLER, A.R. Crescimento e rendimento de duas cultivares de soja em resposta ao arranjo de plantas e regime hídrico. 2000. 108f. Dissertação (Mestrado em Fitotecnia) - Programa de
Pós-graduação em Fitotecnia, Faculdade de Agronomia, Universidade Federal do Rio Grande do Sul.

MATHEW, J.P. et al. Differential response of soybean yield components to the timing of light enrichment. Agronomy Journal, Madison, v.92, n.6, p.1156-1161, 2000.

PEDIGO, L.P.; HUTCHINS, S.H.; HIGLEY, L.G. Economic injury levels in theory and practice. Annual Review of Entomology, Palo Alto, v.31, p.341-368, 1986.

PIRES, J.L.F.; COSTA, J.A.; THOMAS, A.L. Rendimento de grãos de soja influenciado pelo arranjo de plantas e níveis de adubação. Pesquisa Agropecuária Gaúcha, Porto Alegre, v.4, n.2, p.183188, 1998.

PISSAIA, A.; COSTA, J.A. Influência de desfloramentos artificiais sobre o rendimento de grãos e seus componentes em duas cultivares de soja. Pesquisa Agropecuária Brasileira, Brasília, v.16, n.4, p.507-516, 1981.

RIBEIRO, A.L.P.; COSTA, E.C. Desfolhamento em estádios de desenvolvimento da soja, cultivar BR 16, no rendimento de grãos. Ciência Rural, Santa Maria, v.30, n.5, p.767-771, 2000.

THOMAS, A.L.; COSTA, J.A.; PIRES, J.L. Rendimento de grãos de soja afetado pelo espaçamento entre linhas e fertilidade do solo. Ciência Rural, Santa Maria, v.28, n.4, p.543-546, 1998.

VENTIMIGLIA, L.A. et al. Potencial de rendimento da soja em razão da disponibilidade de fósforo no solo e dos espaçamentos. Pesquisa Agropecuária Brasileira, Brasília, v.34, n.2, p.195-199, 1999. 